\title{
High-Rate Blended Cathode with Mixed Morphology for All- Solid-State Li-ion Batteries
}

\author{
Kookjin Heo ${ }^{1,2}$, Jehong $\mathrm{Im}^{1,2}$, Jeong-Seon Lee ${ }^{1}$, Jeonggeon $\mathrm{Jo}^{2}$, Seokhun $\mathrm{Kim}^{2}$, Jaekook Kim², \\ and Jinsub Lim ${ }^{1, *}$ \\ ${ }^{1}$ Korea Institute of Industrial Technology (KITECH), 6, Cheomdan-gwagiro 208-gil, Buk-gu, Gwangju 61012, Republic of Korea \\ ${ }^{2}$ Department of Materials Science and Engineering, Chonnam National University, 300 Yongbongdong, Bukgu, Gwangju \\ 61186, Republic of Korea
}

\begin{abstract}
In this article, we report the effect of blended cathode materials on the performance of all-solid-state lithium-ion batteries (ASLBs) with oxide-based organic/inorganic hybrid electrolytes. $\mathrm{LiFePO}_{4}$ material is good candidates as cathode material in PEO-based solid electrolytes because of their low operating potential of $3.4 \mathrm{~V}$; however, $\mathrm{LiFePO}_{4}$ suffers from low electric conductivity and low $\mathrm{Li}$ ion diffusion rate across the $\mathrm{LiFePO}_{4} / \mathrm{FePO}_{4}$ interface. Particularly, monoclinic $\mathrm{Li}_{3} \mathrm{~V}_{2}\left(\mathrm{PO}_{4}\right)_{3}$ (LVP) is a well-known high-power-density cathode material due to its rapid ionic diffusion properties. Therefore, the structure, cycling stability, and rate performance of the blended $\mathrm{LiFePO}_{4} / \mathrm{Li}_{3} \mathrm{~V}_{2}\left(\mathrm{PO}_{4}\right)_{3}$ cathode material in ASLBs with oxidebased inorganic/organic-hybrid electrolytes are investigated by using powder X-ray diffraction analysis, field-emission scanning electron microscopy, Brunauer-Emmett-Teller sorption experiments, electrochemical impedance spectroscopy, and galvanostatic measurements.
\end{abstract}

Keywords : Blending Effect, All Solid State Battery, $\mathrm{LiFePO}_{4}$ Cathoe Material, $\mathrm{Li}_{3} \mathrm{~V}_{2}\left(\mathrm{PO}_{4}\right)_{3}$ Cathode Material

Received : 20 November 2019, Accepted : 16 March 2020

\section{Introduction}

Secondary lithium ion batteries (LiBs), despite their safety risks, are widely used as power sources from small devices such as smartphones or laptops to energy storage systems and large devices in electric vehicles. Nevertheless, the demand for electric vehicles is increasing recently, and the development of new lithium ion batteries with stable and reliable performance is required [1-4]. However, at present, since most lithium-ion batteries are based on flammable organic liquid electrolytes, the safety issue of LiB is still an important challenge. Thus, all-solid-state lithium-ion batteries (ASLB) are considered one of the promising alternatives for next-generation batteries using non-flammable inorganic-based electrolytes that act on both electrolytes and separators.

*E-mail address: jinsub@kitech.re.kr

DOI: https://doi.org/10.33961/jecst.2019.00661

This is an open-access article distributed under the terms of the Creative Commons Attribution Non-Commercial License (http://creativecommons.org/licenses/by-nc/4.0) which permits unrestricted non-commercial use, distribution, and reproduction in any medium, provided the original work is properly cited.
There are many ways to manufacture ASLBs, including of pellet type and wet slurry process. The wet slurry process is one of the most suitable process for bulk-type ASLBs containing composite electrode and electrolyte and have many advantages, because of similar manufacturing process of the commercialized LiBs, it is possible to manufacture high energy density and the ability to obtain thick electrode. In ASLBs, the solid electrolyte (SE) material are the most important components, because its high ionic conductivity and mechanical properties are important factors governing the appropriate choice of SE matierials [5]. In particular, solid polymer electrolytes (SPEs), in which lithium salt is dissolved have advantages over inorganic solid electrolytes in terms of flexibility, light weight, process, ability, and low cost. Lithium salts $\left(\mathrm{LiClO}_{4}, \mathrm{LiPF}_{6}\right.$ etc. $)$ are dissociated in polymer matrices such as polyethylene oxide (PEO), polyacrylonitrile (PAN), polyvinylidene fluoride (PVDF), and polyvinylpyrrolidone (PVP) to realize lithium ion conduction [6-14]. Despite these advantages, SPE is still remain the problems such as 
low ionic conductivity at room temperature $\left(<10^{-}\right.$ $\left.{ }^{5} \mathrm{~S} \mathrm{~cm}^{-1}\right)$, weak mechanical strength and low potential stability [13].

Due to the unsuitable properties of polymer electrolytes for bulk-type ASLBs, inorganic/organichybrid electrolytes have recently been intensively investigated. PEO has been particularly studied as a polymer material that is used without any added plasticizers. It functions as a binder, and exhibits ionic conductivity, thus affording control of the interface between the electrode construction materials, such as active materials, conductive materials, and inorganic ionic conductors like garnet-type $\mathrm{Li}_{7} \mathrm{La}_{3} \mathrm{Zr}_{2} \mathrm{O}_{12}$ (LLZO), NASICON type $\mathrm{Li}_{1-\mathrm{x}} \mathrm{Al}_{\mathrm{x}} \mathrm{Ti}_{2-\mathrm{x}}\left(\mathrm{PO}_{4}\right)_{3}$ (LATP), and polymeric Li matrices in ASLB fabricated by wet processes $[9,14,15]$.

Inorganic nanoparticles, such as LLZO, play particularly important roles as ionic conducting fillers in PEO-based composite electrolytes, enhancing their electrochemical properties. The PEO-Li salt matrix also reduces interface resistance due to its fast $\mathrm{Li}$-ion conduction pathways, resulting in improved ASLB electrochemical performance [9]. D. H. Kim et al. reported that the composited nano-sized LLZO in an inorganic-organic hybrid composite membrane displays high ionic conductivity $\left(1.93 \times 10^{-3} \mathrm{~S} \mathrm{~cm}^{-1}\right.$ at $70^{\circ} \mathrm{C}$ ) due to the synergy of LLZO inorganic filler in the composite membrane [16].

In ASLB based on PEO for inorganic/organic hybrid composite electrolyte, selecting appropriate cathode materials are limited by the stability window which do not exceed $4 \mathrm{~V}$ vs $\mathrm{Li} / \mathrm{Li}^{+}$[17]. So, $\mathrm{LiFePO}_{4}$ cathode material is the best candidate cathode material for ASLBs based on PEO electrolyte because of its relatively low redox potential of $3.5 \mathrm{~V}$ vs $\mathrm{Li} / \mathrm{Li}^{+}$ [18]. For these reason, many researchers have evaluated the performance of $\mathrm{LiFePO}_{4}$ using various solid electrolyte material such as LLZO+PEO, LAGP+PEO and LLZO+PVDF-HFP inorganic/organic hybrid electrolyte [9,14-16].

However, LFP suffers from intrinsic limitations, such as low electronic conductivity and Li-ion diffusion rates across the $\mathrm{LiFePO} / \mathrm{FePO}_{4}$ interface. In addition, in ASLBs with inorganic-organic hybrid electrolytes, improvement of power density is an important issue because the PEO-based solid electrolytes have low ionic conductivities $\left(<10^{-5} \mathrm{~S} \mathrm{~cm}^{-1}\right.$ at room temperature).

In this respect, we describe a high-power-density cathode material designed by blending for improving the electrochemical performance of the cathode in all-solid-state Li-ion batteries. In the case of a blended cathode, the shortcomings of the parent material can be minimized by blending the two cathode materials, and the blending ratio can be tailored to produce stable high energy and power densities. Particularly, monoclinic $\mathrm{Li}_{3} \mathrm{~V}_{2}\left(\mathrm{PO}_{4}\right)_{3}$ (LVP) material is known as a high-power-density cathode material due to its rapid ionic diffusion properties [19,20]. J. Kang reported that a nano LVP cathode material of carbon-coated nanoparticles/rod-type particles shows impressive rate capabilities because nano-rods and spherical particles may enhance the electrochemical property [20]. J. Jo et al. reported that nano composited LFP-LVP cathode material demonstrated impressive electrochemical performance. In particular, an LFP-LVP cathode shows a remarkable discharge capacity at current density as high as $6.4 \mathrm{C}$ compared to LFP, because particle LVP contributes to improve the performance by having a three-dimensional framework [21].

Therefore, the structure and electrochemical performance of a blended carbon-coated nano- $\mathrm{LiFePO}_{4} /$ LVP (nano-LFP/LVP) cathode material was investigated for use in ASLBs with oxide-based organic/ inorganic hybrid solid electrolytes. A schematic of the all solid-state battery using blended cathode material is illustrated in Fig. 1. The blending of different cathode materials is a promising strategy to design a developed positive electrode. Mixing of more than two cathode materials, such as layeredlayered, layered-spinel, layered-olivine, spinel-olivine, and other compounds, is done to combine the most advantageous properties of individual cathode materials for improving energy or power density, cycle properties and rate capability [23-27]. Fig. 1 illustrates the blending of LFP particles composed of nanoparticles and LVP particles composed of spherical nanoparticles and rod-type morphology. The blended samples exhibited the excellent cycle characteristics of LFP and the excellent high rate characteristics of LVP. LVP cathode material for blending of LFP due to their structural stability at elevated temperature unlike layered structure material owing covalently bonded (PO4)3- units. In case of all solid state battery using PEO binder for organic/inorganic hybrid membrane, electrochemical evaluation has to be at high temperature above $70^{\circ} \mathrm{C}$. Therefore, LVP 

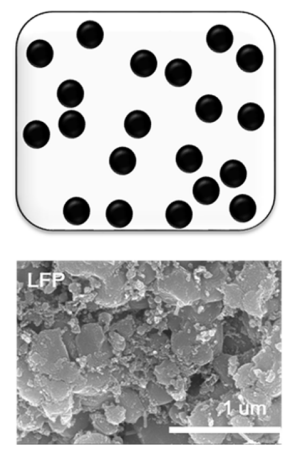
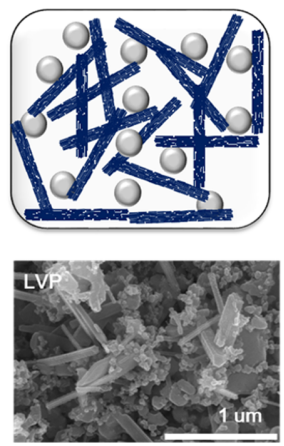
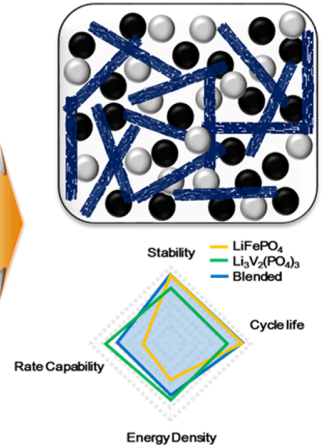

Fig. 1. Schematic diagram of blended material. Nanoparticle LFP and nano-rod type LVP cathode material are blended.

cathode material having great structural stability can attribute to enhance characteristic of LFP cathode material in all solid state battery. The structure can be expected to have high capacity characteristics, making it suitable for use in electric vehicles, and high rate characteristics allowing rapid charging and discharging [20-22]. These materials were examined by Powder X-ray Diffraction (PXRD), Field-Emission Scanning Electron Microscopy (FE-SEM), Electrochemical Impedance Spectroscopy (EIS), and galvanostatic measurements.

\section{Experimental}

\subsection{Materials}

\subsubsection{Electrode Materials}

Synthesis of $\mathrm{LiFePO}_{4}$ : $\mathrm{LiFePO}_{4}$ (LFP) cathode material was selected as the partner material and was synthesized by an advanced sol-gel method in the pilot plant (HELFP-1000) of the Energy Materials Co., Ltd., in which carbon content was $2.5 \mathrm{wt} \%$.

Synthesis of $\mathrm{Li}_{3} \mathrm{~V}_{2}\left(\mathrm{PO}_{4}\right)_{3}$ : The carbon-coated $\mathrm{Li}_{3} \mathrm{~V}_{2}\left(\mathrm{PO}_{4}\right)_{3}$ (LVP) nanocomposite used for the blended electrode was synthesized by the polyol synthesis approach using lithium acetate $\left(\mathrm{C}_{2} \mathrm{H}_{3} \mathrm{LiO}_{2}, \geq\right.$ 99\%; Aldrich), vanadium acetylacetonate $\left(\mathrm{C}_{15} \mathrm{H}_{21} \mathrm{O}_{6} \mathrm{~V}, 97 \%\right.$; Aldrich), and phosphoric acid $\left(\mathrm{H}_{3} \mathrm{PO}_{4}, \geq 85 \%\right.$; Daejung) as starting materials. Firstly, the starting precursors were dissolved in $80 \mathrm{~mL}$ of ethylene glycol $\left(\mathrm{C}_{2} \mathrm{H}_{6} \mathrm{O}_{2}, \geq 99 \%\right.$; Daejung) in the molar ratio $1.5: 1: 1.5(\mathrm{Li}: \mathrm{V}: \mathrm{P})$ at room temperature. After obtaining a homogenous solution, the final solution was uniformly poured onto a hot-plate maintained at $200^{\circ} \mathrm{C}$. The polyol precursor solution was ignited with a torch to induce self-extinguishable combustion. Subsequently, the as-prepared powder was annealed at $800^{\circ} \mathrm{C}$ for $5 \mathrm{~h}$ in argon atmosphere to obtain the LVP/C powders with high crystallinity.

Blended Cathode Material: The LFP was mechanically blended with LVP nanocomposite in 8:2 (LFP/ LVP) weight ratio using a Thinky Mixer (ARE-310).

\subsubsection{Composite Membrane}

$\mathrm{Li}_{7} \mathrm{La}_{3} \mathrm{Zr}_{2} \mathrm{O}_{12}$ (LLZO) powder (cubic structure, 99.9\%, D50: 10 mm, Toshima in Japan) was used as the solid electrolyte. We have used PEO (Mn 1/4 200 $\mathrm{K}$, Sigma-Aldrich) as a polymer binder, and it was mixed by mechanical blending using Thinky Mixer at $2000 \mathrm{rpm}$ for $5 \mathrm{~min}$. To prepare the composite membrane, a $\mathrm{PEO} / \mathrm{LiClO}_{4}$ mixture (molar ratio = 20:1) was used, with added LLZO (30 wt\% with respect to $\mathrm{PEO} / \mathrm{LLZO}$ ). $\mathrm{PEO}$, as the polymer binder, was first dissolved in acetonitrile (ACN, Aldrich Co. Ltd.), after which $\mathrm{LiClO}_{4}$ (as a salt) was homogenously added to the PEO slurry using the abovementioned Thinky Mixer. The appropriate amount of LLZO powder was then added to the $\mathrm{PEO} / \mathrm{LiClO}_{4}$ slurry, after which it was thoroughly mixed. The slurry containing PEO, $\mathrm{LiClO}_{4}$, and LLZO in ACN was cast onto a Mylar film (SKC co. Ltd, coated $\mathrm{SiO}_{2}$ ) and ACN was evaporated at room temperature to obtain the approximately 150 -mm-thick composite membrane for use as the separator and electrolyte.

\subsection{Structural and Physical Characterization}

Powder X-ray Diffraction: The obtained samples were analyzed by powder X-ray diffraction using an X'pert Pro X-ray diffractometer (PANalytical) with 
Ni-filtered $\mathrm{Cu}$ Ka radiation $(1=1.5406 \AA)$, operated at $40 \mathrm{kV}$ and $30 \mathrm{~mA}$ within a scanning angle $(2 \theta)$ range $10-80^{\circ}$ using step size $=0.01^{\circ}$. High Score Plus software was used to determine the unit-cell parameters of the samples.

Electron microscopy (FE-SEM): Particle morphologies and sizes were determined using field emission-scanning electron microscopy (FE-SEM). SEM images were obtained using an S-4700 instrument (HITACHI) and an energy-dispersive X-ray spectrometer (EDS).

\subsection{Electrochemical Measurements}

The electrochemical properties of the LFP and the blended sample were examined using lithium metal as reference and counter electrodes. The active material (pure LFP or blended), solid electrolyte (LLZO), conductive carbon (super P), and polyethylene oxide (PEO) binder were used in a stoichiometric ratio of 70:5:5:20 to fabricate the electrode. LLZO in the positive electrode improves the lithium ion conductivity of the electrode and provides a path through which lithium ion can move. The stoichiometrically mixed slurry was cast onto $\mathrm{Al}$ foil and then dried at room temperature to form the cathode. A 2032 coin-type cell, consisting of the cathode and the lithium-metal anode separated by the composite membrane sheet, prepared as described above, was fabricated in a dry room and aged for $12 \mathrm{~h}$ prior to the electrochemical experiment. The charge-discharge measurements of the prepared coin-type cell were performed over the potential range from 2.5 to $4.0 \mathrm{~V}$ due to discharging to $2.5 \mathrm{~V}$ in $\mathrm{Li} / \mathrm{LiFePO}_{4}$ cell vs. $\mathrm{Li}^{+} / \mathrm{Li}$ at different current densities using Wonatech WBCS 3000L.

Electrochemical impedance spectroscopy (EIS) was carried out at $70^{\circ} \mathrm{C}$ using a Bio-Logic Science instrument (SP-150) to determine variations in resistance in the assembled coin cell. The cell was tested during the first and $50^{\text {th }}$ cycles and examined at each cycle over the frequency range from $100 \mathrm{mHz}$ to $1.0 \mathrm{MHz}$.

\section{Results and Discussion}

Fig. 2 shows the XRD patterns of LFP, LVP and blended cathode material. The patterns shown in Fig. 2(a), (b) are indexed to the single-phase orthorhombic structure (space group: Pnma) of LFP and the

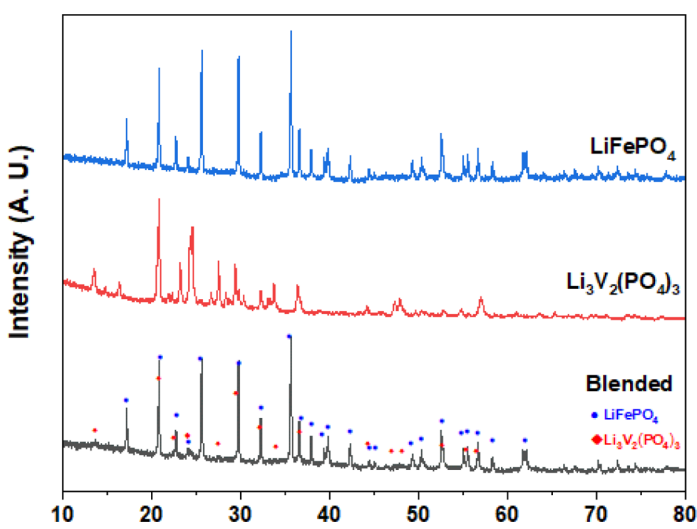

Fig. 2. Powder X-ray diffraction patterns of (a) $\mathrm{LiFePO}_{4}$ cathode material, (b) $\mathrm{Li}_{3} \mathrm{~V}_{2}\left(\mathrm{PO}_{4}\right)_{3}$ cathode material, and (c) blended cathode material.

monoclinic structure (space group: $\mathrm{P} 2{ }_{1} / \mathrm{n}$ ) of LVP, respectively. As shown in Fig. 2(c), the blended LFP/ LVP sample exhibits reflections that coincide with those of the two components, LFP and LVP materials. The intensities of the LVP signals in the blended sample are also lower than those of the LFP, due to the comparatively low proportion of LFP in the blend. These results confirm that the peaks observed for the blend are well matched with those of the crystal structures of the active materials (LVP and LFP); no peak shifts or evidence of any impurity were observed.

The morphology and homogeneous distribution of the blended material was investigated by using FESEM (Fig. 3); the SEM images show the shapes and sizes of the LFP and LVP particles, and the particles in the blended material. LFP is composed of particles several nanometers in size; the high-magnification images also revealed the presence of agglomerated secondary particles and carbon particles (Fig. 3(a), (b)). The LVP cathode material contained several nanometer-sized well agglomerated secondary particles and rod-type particles dispersed among a majority of apparently smaller particles with spherical morphologies, as shown in Fig. 3(c), (d). The rod-type particles are observed to range from a few hundred nanometers to micrometers in size and are composed of carbon particles. Fig. 3(e), (f) show low- to high-magnification images of blended cathode material, which reveal that the blended material consists of homogenously distributed LFP and LVP particles, with the nano-rod LVP covering the surface 


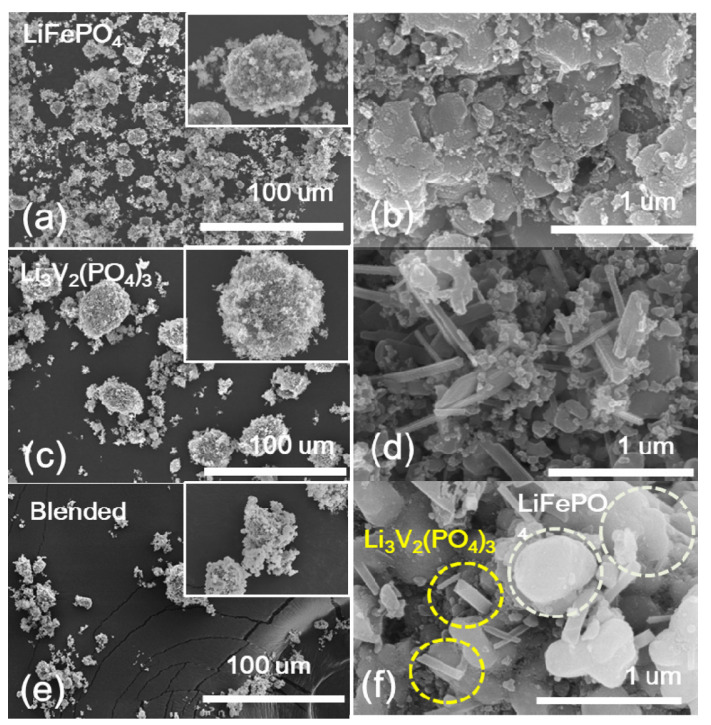

Fig. 3. SEM images of (a) $\mathrm{LiFePO}_{4}$, (b) $\mathrm{Li}_{3} \mathrm{~V}_{2}\left(\mathrm{PO}_{4}\right)_{3}$, and (c) blended cathode material. of LFP nanoparticles aggregated with each other. These nano-rod LVP particles impact on good electrochemical performance because the rod-type particles may offer better between particle connectivity $[20,22]$. Elemental mapping using energy-dispersive $\mathrm{X}$-ray spectroscopy (EDS) was performed to investigate the distribution of chemical elements in the blended cathode material (Fig. 4). Fe, V, P, C, and O were uniformly distributed in the material. The images reveal that the LVP and LFP materials were well blended without heat; carbon is well dispersed in the sample, similar to the distributions of $\mathrm{Fe}, \mathrm{V}$ and $\mathrm{P}$.

Fig. 5 presents the electrochemical performance of the LFP and blended electrode vs. $\mathrm{Li}^{0} / \mathrm{Li}^{+}$. The LFP and blended electrode were cycled over a potential range from 2.5 to $4.0 \mathrm{~V}$ at $0.1 \mathrm{C}$-rate at $70{ }^{\circ} \mathrm{C}$ temperature. To exclude the effect of the PEO binder, $\mathrm{Li}^{+}$ had to be extracted from the LFP and blended electrode at below $4.0 \mathrm{~V}$ vs. $\mathrm{Li}^{0} / \mathrm{Li}^{+}$, because inorganic/

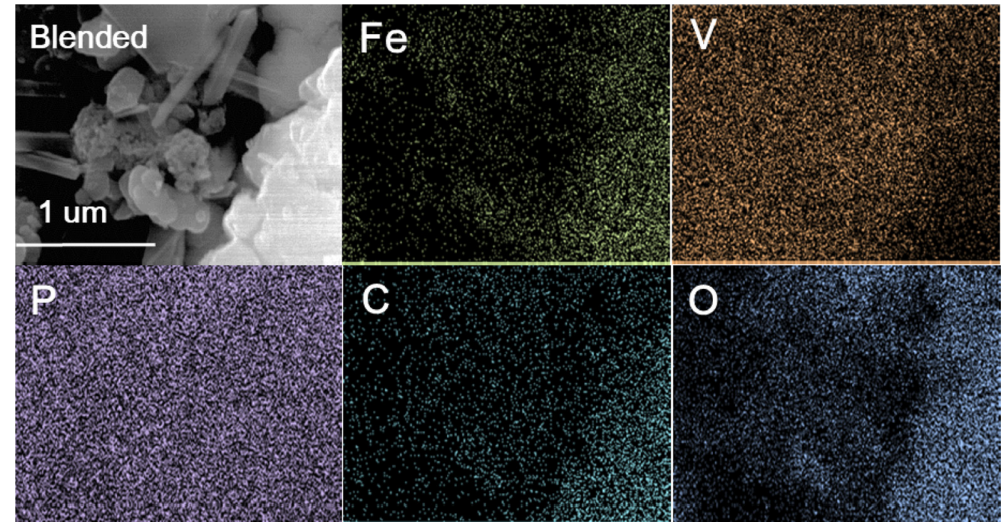

Fig. 4. EDS mapping images of the blended cathode material showing distributions of Fe, V, P, C, and O.
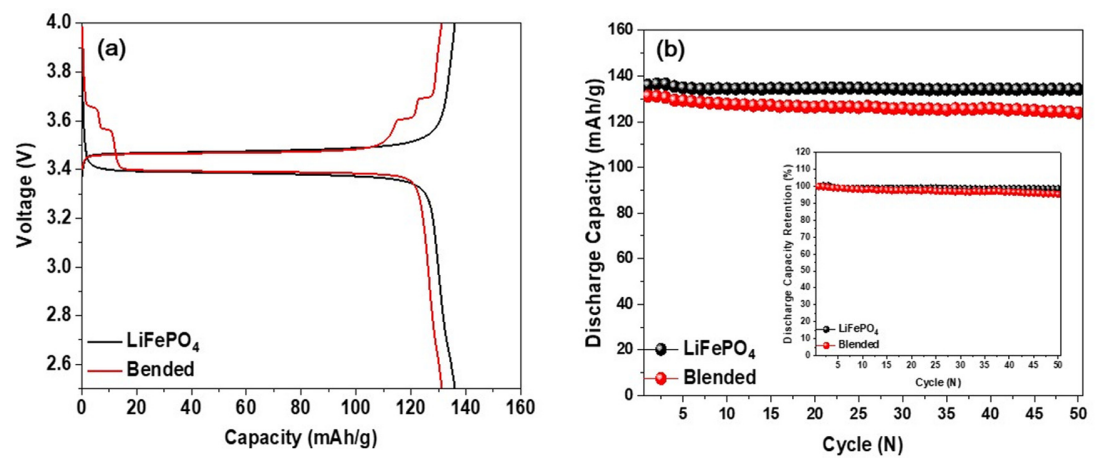

Fig. 5. (a) Initial charge-discharge curves for $\mathrm{LiFePO}_{4}$ and the blended cathode material over a voltage range from $2.5 \mathrm{~V}$ to $4.0 \mathrm{~V}$ at $0.1 \mathrm{C}$ at $70^{\circ} \mathrm{C}$. (b) Cycling performance of $\mathrm{LiFePO}_{4}$ and the blended cathode material over 50 cycles over a voltage range $2.5-4.0 \mathrm{~V}$ at $0.2 \mathrm{C}$ at $70^{\circ} \mathrm{C}$. 
organic-hybrid composite electrolytes in ASLBs are restricted to the stability window of the PEO-based electrolyte which cannot exceed $4.0 \mathrm{~V}$ vs. $\mathrm{Li}^{0} / \mathrm{Li}^{+}$ [17]. The initial discharge capacities of the LFP and blended electrodes were determined to be 135.98 and $131.26 \mathrm{mAh} \mathrm{g}^{-1}$, respectively as shown in Fig. 5(a). The voltage profiles indicate that a plateau is formed at around 3.4 V for the LFP electrode. However, the blended electrode showed two lower plateaus at 3.63 and $3.71 \mathrm{~V}$ that correspond to the two-step extraction of one Li from LVP and reveal the presence of mixed $\mathrm{V}(\mathrm{III}) / \mathrm{V}(\mathrm{IV})$ oxidation states. On the other hand, 3.66 and $3.56 \mathrm{~V}$ correspond to the re-insertion of the $\mathrm{Li}$ ion into the monoclinic host and complete reduction from V(III) to V(IV) state in the monoclinic structure. In the first discharge curve, its initial discharge capacity is almost equivalent to the sum of the proportion values of their ratio, namely $80 \%$ of $104 \mathrm{mAh} \mathrm{g}^{-1}$ (LFP) $+20 \%$ of $26 \mathrm{mAh} \mathrm{g}^{-1}$ (LVP). It can be clearly seen that the mechanical blending method performed without heat treatment was effectively carried out. Fig. 5(b) indicates the cycle properties of the LFP and blended electrodes, determined at a rate of $0.2 \mathrm{C}$ in the 2.5-4.0 $\mathrm{V}$ potential window, at $70^{\circ} \mathrm{C}$ during 50 cycles. Scrosati's group reported that the LFP cathode material used as the reference electrode in this study is a good candidate material for ASLBs with PEO-based electrolytes, because of its relatively low redox potential window of $3.5 \mathrm{~V}$ vs $\mathrm{Li}^{0} / \mathrm{Li}^{+}[18]$. It is seen to have excellent discharge capacity retention of $98.6 \%$ after 50 cycles, as shown in Fig. 5(b).

Fig. 6 displays the differential capacity $(\mathrm{dQ} / \mathrm{dV})$ as functions of cell voltage for these electrodes at the first and $50^{\text {th }}$ cycles. The LFP cathode exhibits oxida- tion and reduction peaks at 3.49 and $3.35 \mathrm{~V}$, respectively, in the first cycle. The blended cathode material, on the other hand, showed LVP peaks at 3.48, 3.63, and 3.71 V (cathodic peak) and 3.37, 3.56, and $3.66 \mathrm{~V}$ (anodic peak) that correspond to the twophase transition of the $\mathrm{V}(\mathrm{III}) / \mathrm{V}(\mathrm{IV})$ redox couple, but LFP peaks that appeared at the same voltages as those of the pure LFP sample. After 50 cycles, the LFP and LVP redox peaks in the blended cathode material were largely unaffected. The intensities of the LFP redox peaks do not decrease after 50 cycles, because the LFP cathode material has good cycle stability characteristic as represented by Fig. 5(b).

To affirm the availability of the LFP/LVP blend in improving the rate capability of the LFP and blended electrode, rate measurements were performed at various current rates, with the results shown in Fig. 7. Fig. 7(a) show the discharge capacity retention rate for each current of the LFP and blended cathode material, and Fig. 7(b), (c) reveal the charge/discharge capacity curves of the LFP and blended cathode material, respectively. At low current rates of about 0.1 and $0.2 \mathrm{C}$, the capacity retention of the two electrodes do not differ significantly. Since LFP material has strong $\left(\mathrm{PO}_{4}\right)^{3-}$ bonding, there is almost no structural change as charging and discharging progresses, improving structural stability. Therefore, it is thought that the difference in discharge capacity retention rate does not show much in low current regions such as 0.1 and $0.2 \mathrm{C}$. However, as the current rates increase over $0.5 \mathrm{C}$, the capacity retention ratio of the two electrodes show a large difference. In the LFP sample, the discharge capacity retention rates are shown to be $40 \%(0.5 \mathrm{C})$ and $30 \%(1 \mathrm{C})$. However, in the blended samples, the discharge
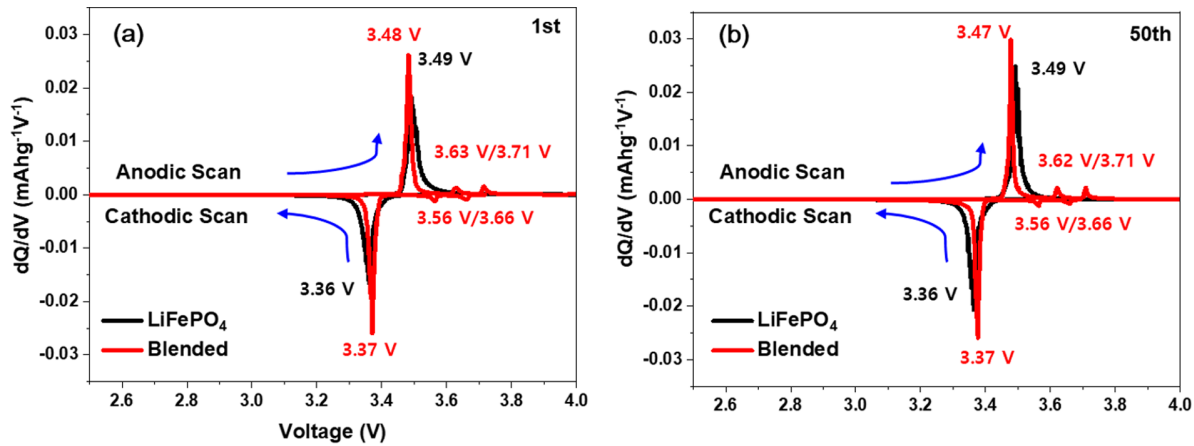

Fig. 6. Differential capacities of $\mathrm{LiFePO}_{4}$ and the blended cathode material as functions of voltage at (a) the first cycle and (b) the $50^{\text {th }}$ cycle, in the $2.5-4.0-\mathrm{V}$ potential range at $70^{\circ} \mathrm{C}$. 

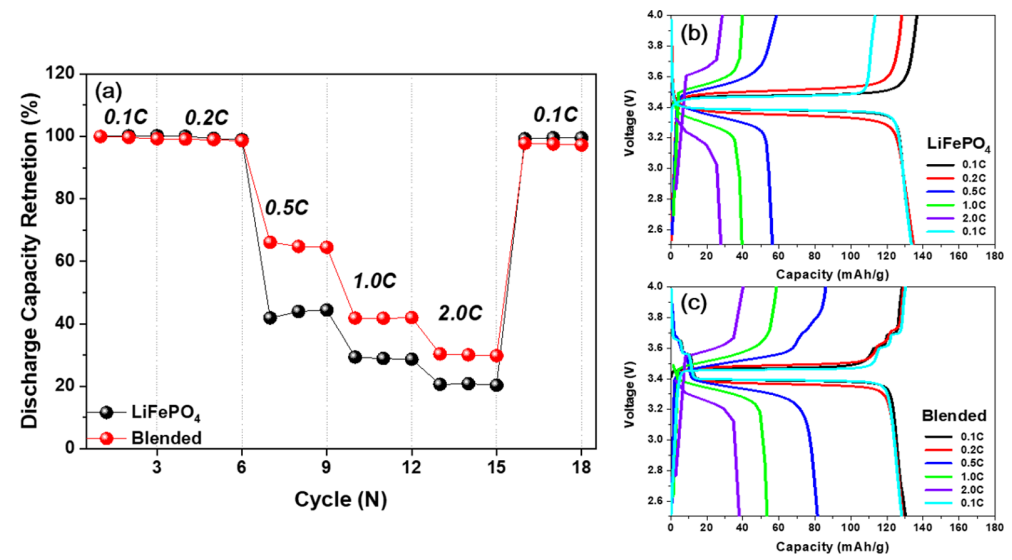

Fig. 7. Rate capability of $\mathrm{LiFePO}_{4}$ and blended cathode material was determined in a voltage range from $2.5 \mathrm{~V}$ to $4.0 \mathrm{~V}$ at various current rates between 0.1 and $10 \mathrm{C}$ at $70^{\circ} \mathrm{C}$. (a) Discharge capacity retention of $\mathrm{LiFePO}_{4}$ and the blended cathode material. Charge/discharge curves at various current rates of (b) $\mathrm{LiFePO}_{4}$ and (c) the blended cathode material.
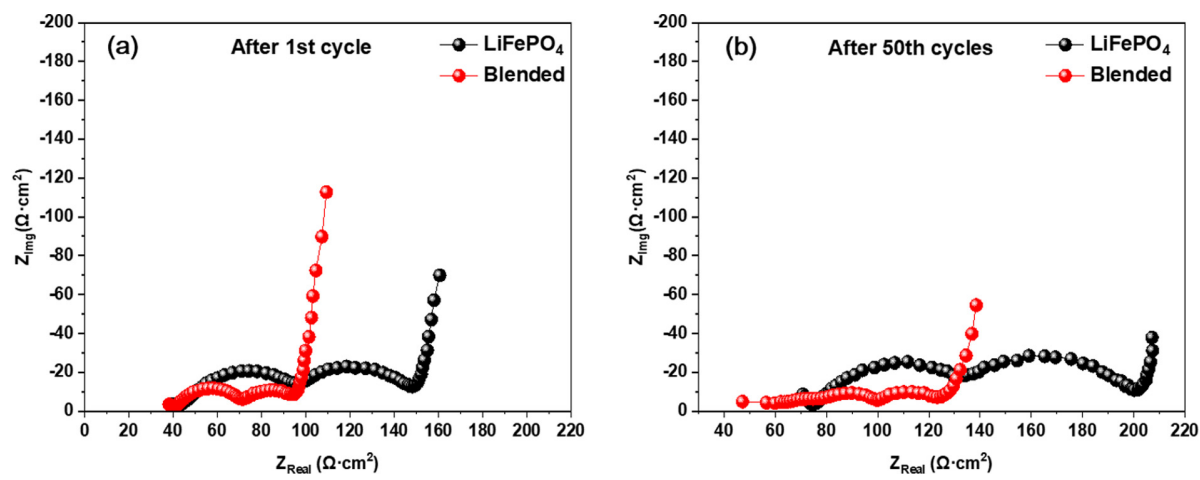

Fig. 8. EIS spectra of assembled coin cells $\left(\mathrm{Al} / \mathrm{LiFePO}_{4}\right.$ or blended/PEO- $\mathrm{LiClO}_{4} / \mathrm{Li}$ metal $)$ recorded over the frequency range from $100 \mathrm{mHz}$ to $1 \mathrm{MHz}$ for (a) $\mathrm{LiFePO}_{4}$ and the blended electrode at the first cycle, and (b) $\mathrm{LiFePO}_{4}$ and the blended cathode material at the $50^{\text {th }}$ cycle.

capacity retention was $60 \%(0.5 \mathrm{C})$ and $40 \%(1 \mathrm{C})$, which shows better discharge capacity retention as the current rate increases than LFP. These improvements are associated with the LVP cathode material. Contained carbon source LVP cathode material contributes to the enhanced lithium ion diffusion, and the presence of rod-shaped particles in addition to nanosized particles can provide better bonding between particles and contribute to improvement of electrochemical performance. Polyol combustion is a method of providing spontaneous ultra-high energy to promote nucleation and grain growth of amorphous particles; after heat treatment, amorphous LVP is converted into highly crystalline LVP nanoparticles. Carbonized structures formed as a result of polyol combustion tend to inhibit particle growth because they can act as barriers. These carbon particles penetrate between the spherical particles and the energy transfer from the additional carbon particles is faster, so that the particle growth in rod form is relatively easy, and as a result, many rod type particles are generated. In addition to nano-sized particles, rod-type particles can contribute to providing intergranular connectivity and improving electrochemical performance [20,22].

In order to investigate variations in resistance during cycling in an assembled coin cell, electrochemical impedance spectroscopy (EIS) was carried out at $70^{\circ} \mathrm{C}$. Fig. 8 indicated the EIS spectra of assembled coin cell (Al/pure LFP or blended//PEO- 
$\mathrm{LiClO}^{+} / / \mathrm{Li}$-metal) recorded over the $100 \mathrm{mHz}-$ $1 \mathrm{MHz}$ range, for the first cycle and the $50^{\text {th }}$ cycle. The Nyquist plots display typical semicircles at high and medium frequencies and an inclined line in the low-frequency region that corresponds to the interfacial resistance associated with lithium-ion diffusion in the bulk material. The lithium-ion diffusion through the surface $\left(R_{s}\right)$ is reflected in the first semicircle. The second semicircle is associated with charge-transfer resistance $\left(\mathrm{R}_{\mathrm{ct}}\right)[28,29]$. The charge transfer impedance of the first charge and discharge cycles for LFP and blended electrode were found to be 147.08 and $93.94 \Omega \mathrm{cm}^{-2}$, respectively as shown in Fig. 8(a). After 50 cycles, as shown in Fig. 8(b), the charge transfer resistance values of the LFP and blended samples increased to 200.27 and $124.61 \Omega \mathrm{cm}^{-2}$, respectively. This is because the resistance inside the electrode increases due to the insertion and desorption of lithium as the cycles progress. However, even after 50 cycles, the resistance of the blended sample is significantly lower than that of the LFP electrode because nano-rod type LVP particles affect the relatively efficient particleparticle contacts leading to a decreased charge transfer resistance [20,22].

\section{Conclusions}

In summary, we investigated a blended cathode material composed of LFP and LVP cathode material for use in all-solid-state lithium-ion batteries with an oxide-based solid electrolyte. The XRD pattern of the blended sampled exhibited reflection that coincide with those of the two component materials of LFP and LVP without any peak shift and impurities. FESEM images reveal that the blended material consists of LFP and LVP particles that are homogenously distributed, with the nano-rod LVP covering the surface of LFP nanoparticles aggregated with each other. These nano-rod LVP particles impact good electrochemical performance because the rod-type particles may offer better inter-particle connectivity. The voltage profiles of blended cathode material indicate that plateaus are formed at around 3.4 V for the LFP electrode. However, the blended electrode showed two lower plateaus at 3.6 and $3.68 \mathrm{~V}$ that correspond to the two-step extraction of one Li from LVP and reveal the presence of mixed V(III)/V(IV) oxidation states. The rate capability results reveal that for the blended samples, the discharge capacity retention was $60 \%(0.5 \mathrm{C})$ and $40 \%$ (1C), which shows better discharge capacity retention as the current rate increases than LFP. These improvements are associated with the LVP cathode material. Contained carbon source LVP cathode material contributes to the enhanced lithium-ion diffusion. Further, the presence of rod-shaped particles in addition to nano-sized particles can provide better bonding between particles and contribute to improvement of electrochemical performance. Therefore, blended cathode material shows a low charge transfer resistance compared to LFP cathode material after the first and $50^{\text {th }}$ cycles due to nano-rod type LVP particles affecting the relatively efficient particle-particle contacts and leading to a decreased charge transfer resistance.

\section{Acknowledgments}

This work was supported by Korea Institute of Energy Technology Evaluation and Planning (KETEP) grant funded by the Korea government (MOTIE) (20182020109950, The Development of High Strength Lightweight Aluminum Battery Package and PCM-BTMS for High Safety and Battery Efficiency Improvement of Electrical Vehicle).

\section{Supporting Information}

Supporting Information is available at https:// doi.org/10.33961/jecst.2019.00661

\section{References}

[1] K. Heo, J. S. Lee, H. S. Kim, J. Kim and J. Lim, J. Electrochem, Soc., 2017, 164(12), A2398-2402.

[2] M. Armand and J.M. Tarascon, Nature, 2008, 451(7179), 652-657.

[3] K. Takada, Acta Mater, 2013, 61(3), 759-770.

[4] B. L. Ellis, K. T. Lee, and L. F. Nazar, Chem. Mater, 2010, 22(3), 691-714.

[5] W. Zhanga, J. Niea, F. Lic, Z.L. Wanga, and C. Sun, Nano Energy, 2018, 45, 413-419.

[6] F. Croce, G.B. Appetecchi, L. Persi, and B. Scrosati, Nature, 1998, 394(6692), 456-458.

[7] T. Stergiopoulos, I.M. Arabatzis, G. Katsaros, and P. Falaras, Nano Lett., 2002, 2(11), 1259-1261.

[8] Z. Jiang, B. Carroll and K. M. Abraham, Electrochim. Acta, 1997, 42(17), 2667-2677.

[9] X.Ben, W. Zhang, N. Chen and C. Sun, J. Phys. Chem., 2018, 122(18), 9852-9858. 
[10] P. Raghavan, J. Manuel, X. Zhao, D.S. Kim, J.H. Ahn, and C. Nah, J. Power Sources, 2011, 196(16), 67426749.

[11] H.S. Jeong, D.W. Kim, Y.U. Jeong, and S.Y. Lee, J. Power Sources, 2010, 195(18), 6116-6121.

[12] S.W. Choi, S.M. Jo, W.S. Lee, and Y.R. Kim, Adv. Mater, 2003, 15(23), 2027-2032.

[13] Y. Wang and W.H. Zhong, ChemElectroChem, 2015, 2(1), 22-36.

[14] J.H. Choi, C.H. Lee, J.H. Yu, C.H. Doh, and S.M. Lee, J. Power Sources, 2015, 274, 458-463.

[15] D. Zhang, L. Zhang, K. Yang, H. Wang, C. Yu, D. Xu, B. Xu, and L. M. Wang, ACS Appl. Mater. Interfaces, 2017, 9(42), 36886-36896.

[16] D. H. Kim, M. Y. Kim, S. H. Yang, H, M. Ryu, H. Y. Jung, H. J. Ban, S. J. Park, J. Lim, and H. S. Kim, J. Ind. Eng. Chem., 2019, 71, 445-451.

[17] K. Hanai, K. Kusagawa, M. Ueno, T. Kobayashi, N. Imanishi, A. Hirano, Y. Takeda, and O. Yamamoto, J. Power Sources, 2010, 195(9), 2956-2960.

[18] F. Croce, F.S. Fiory, L. Persi, and B. Scrosati, Electrochem. Solid State Lett., 2001, 4(8), A121-A123.

[19] S. Kim, J, Song, B, Sambandam, S. Kim, J. Jo, S. Park, S. Baek, and J. Kim, Mater. Today Commun., 2017, 10, 105-111.
[20] J. Kang, V. Mathew, J. Gim, S. Kim, J. Song, W. B. Im, J. Han, J. Y. Lee, and J. Kim, Sci. Rep.,2014, 4, 4047.

[21] J. Jo, J. Gim, J. Song, Y. Kim, V. Mathew, S. Kim, S. Kim, S. Park, J. P. Baboo, and J. Kim, Ceram. Int., 2017, 43(5), 4288-4294.

[22] J. Lim, V. Mathew, K. Kim, J. Moon, and J. Kim, J. Electrochem. Soc., 2011, 158(6), A736-A740.

[23] K.-S. Lee, S.-T. Myung, D.-W. Kim, and Y.-K. Sun, J. Power Sources, 2011, 196(16), 6974-6977.

[24] A. Klein, P. Axmann, and M. Wohlfahrt-Mehrens, $J$. Power Sources, 2016, 309, 169-177.

[25] K.G. Gallagher, S.-H. Kang, S.U. Park, and S.Y. Han, J. Power Sources, 2011, 196, 9702-9707.

[26] C. Heubner, T. Leibmann, M. Schneider and A. Michaelis, Electrochim. Acta, 2018, 269, 745-760.

[27] L. Liu, W. Xiao, M. Chen, H. Chen, Y. Cui, G. Zeng, Y. Chen, X. Ke, Z. Guo, Z. Shi, H. Zahng and S. Chou, J. Alloy and Compds, 2017, 719, 281-287.

[28] Q.X. Du, Z.F. Tang, X.H. Ma, Y. Zang, X. Sun, Y. Shao, Z.Y. Wen, and C.H. Chen, Solid State Ionics, 2015, 279, 11-17.

[29] J.S. Lim, J.H. Gim, J.J. Song, D.T. Nguyen, S.J. Kim, J.G. Jo, V. Mathew, and J.K. Kim, J. Power Sources, 2016, 304, 354-359. 